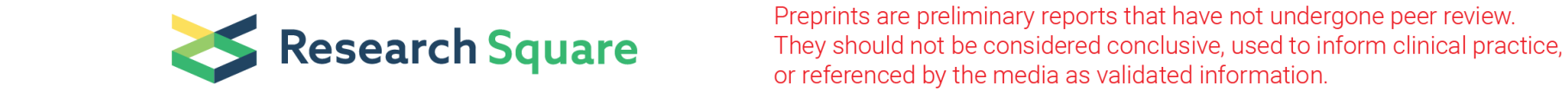

\title{
Peritoneal inclusion cyst: a rare occurrence in incisional hernia
}

Kaumudi Konkay ( $\square$ kaumudi_9@yahoo.com )

Guntur Medical College https://orcid.org/0000-0003-3058-7159

Vijayasree Mandava

Guntur Medical College

Priya Madhooli swargam

Guntur Medical College

\section{Research Article}

Keywords: Peritoneal inclusion cysts, incisional hernia

Posted Date: February 16th, 2022

DOl: https://doi.org/10.21203/rs.3.rs-220196/v1

License: (1) This work is licensed under a Creative Commons Attribution 4.0 International License. Read Full License 


\section{Abstract}

Peritoneal inclusion cysts are cysts of mesenteric origin and usually have an indolent course. They can occasionally become symptomatic depending on their size and location. We present a rare case of Peritoneal inclusion cyst presenting as Incisional hernia. This is the first reported case of Peritoneal inclusion cyst presenting as incisional hernia to the best of our knowledge.

\section{Introduction}

Peritoneal inclusion cysts are cysts of mesenteric origin and usually have an indolent course. They can occasionally become symptomatic depending on their size and location. There are several case reports of Peritoneal cysts presenting as inguinal and femoral hernia [1, 2]. We present a rare case of Peritoneal inclusion cyst presenting as Incisional hernia. This is the first reported case of Peritoneal inclusion cyst presenting as incisional hernia to the best of our knowledge.

\section{Case Report}

A 31-year-old female presented with irreducible incisional hernia from previous Caesarean section scar. Ultrasonography revealed a high placed right tubo ovarian complex with irreducible herniation of part of ovary tube complex through infra umbilical, Para incisional parietal wall. Uterus was bulky and showed features suggestive of Adenomyosis.

Laparotomy was done and hysterectomy with excision of, right? Tubo-ovarian complex was done.

On gross examination, the uterus was bulky measuring $10 \times 10 \times 7 \mathrm{~cm}$. Myometrium was thickened measuring $4.5 \mathrm{~cm}$. Endometrium was $0.2 \mathrm{~cm}$ thick. Both the tubes appeared grossly normal. A separate fragment of peritoneum showed tiny cysts ranging from 0.3 to $0.5 \mathrm{~cm}$ filled with serous fluid (Fig. 1a).

On microscopy, the uterus showed Adenomyosis. Peritoneum revealed cysts lined by mesothelium and surrounded by fibrocollagenous tissue (Fig. 1b). Focal areas of chronic inflammatory infiltrate were seen. The final diagnosis of uterine adenomyosis with peritoneal inclusion cyst adherent to fallopian tubes was given.

The patient was discharged on the seventh postoperative day and her postoperative course was uneventful and the patient is stable and doing well.

\section{Discussion}

Peritoneal inclusion cysts are rare benign cysts of mesenteric origin with less than 1000 cases reported in literature. [3] They are usually asymptomatic but can become symptomatic when they grow in size; can reach upto $40 \mathrm{~cm}$ in size [4] and when they undergo rupture, torsion or get infected.

They usually occur in women in reproductive age. There are several theories on their origin. One theory is that they arise from congenital incomplete fusion of peritoneal surfaces.[4] Another theory is that they arise due to collection of fluid in peritoneal adhesions formed secondary to pelvic surgery / endometriosis / pelvic inflammatory disease. [4] The second theory holds good in our case since our patient had a previous Caesarean section, and fluid accumulation in the adhesions might have caused a peritoneal cyst which presented as hernia. Another theory is that it develops from proliferation of ectopic lymphatic in mesentery which does not have connection with the lymphatic system [6]

There are less than 10 reported cases of mesenteric cysts presenting as inguinal hernia. [6] Our case is the first case of peritoneal cyst presenting as incisional hernia, and clinically and radiologically masquerade as tubo-ovarian complex which turned out to be peritoneal inclusion cyst on histopathology. Owing to its rarity, it is difficult to diagnose it clinically and radiologically and histopathology is essential for confirming the diagnosis and also for excluding other malignancies.

When symptomatic, Peritoneal inclusion cyst should be excised completely, since incomplete excision can lead to recurrence.[6] To conclude, though extremely rare, it is important to consider Peritoneal inclusion cyst in differential diagnosis of contents of hernia since its incomplete excision can lead to recurrence. [6]

\section{Declarations}


Funding - no funding/ grants received

Conflicts of interest/Competing interests - none

Availability of data and material (data transparency) - Data available on request from the authors

Code availability (software application or custom code)- not applicable

Consent for publication: patient gave written consent for their personal or clinical details along with any identifying images to be published in this study.

\section{References}

1. ArmstrongO.(2010).Peritoneal cyst mimicking a femoral hernia. Hernia: the journal of hernias and abdominal wall surgery,14(4),449451.https://doi.org/10.1007/s10029-010-0678-8

2. Dellaportas,D.,Polymeneas,G.,Dastamani,C.,Kairi-Vasilatou,E.,\&Papaconstantinou,I. (2012).Strangulatedfemoralherniaturnedtobeperitonealcyst.Casereportsinsurgery,2012,528780.https://doi.org/10.1155/2012/528780

3. Sahin,D. A.,Akbulut,G.,Saykol,V.,San,O.,Tokyol,C.,\&Dilek,O. N.(2006).Laparoscopic enucleation of mesenteric cyst: a case report.The Mount Sinai journal of medicine, New York,73(7),1019-1020.

4. Tan,J. J.,Tan,K. K.,\&Chew,S. P.(2009).Mesenteric cysts: an institution experience over 14 years and review of literature.World journal of surgery,33(9),1961-1965.https://doi.org/10.1007/s00268-009-0133-0

5. Lee,S. W.,Lee,S. J.,Jang,D. G.,Yoon,J. H.,\&Kim,J. H.(2012).Comparison of laparoscopic and laparotomic surgery for the treatment of peritoneal inclusion cyst.International journal of medical sciences,9(1),14-19.https://doi.org/10.7150/ijms.9.14

6. GrossRE.The surgery of infancy and childhood.Philadelphia, Pa:WB Saunders Co;1953.pp.377-383.

7. Obaidah,A.,Mane,S. B.,Dhende,N.,Acharya,H.,Thakur,A.,Arlikar,J.,\&Reddy,S.(2012).Mesentric cyst- an unusual presentation as inguinal hernia.The Indian journal of surgery,74(2),184-185.https://doi.org/10.1007/s12262-011-0247-0

\section{Figures}

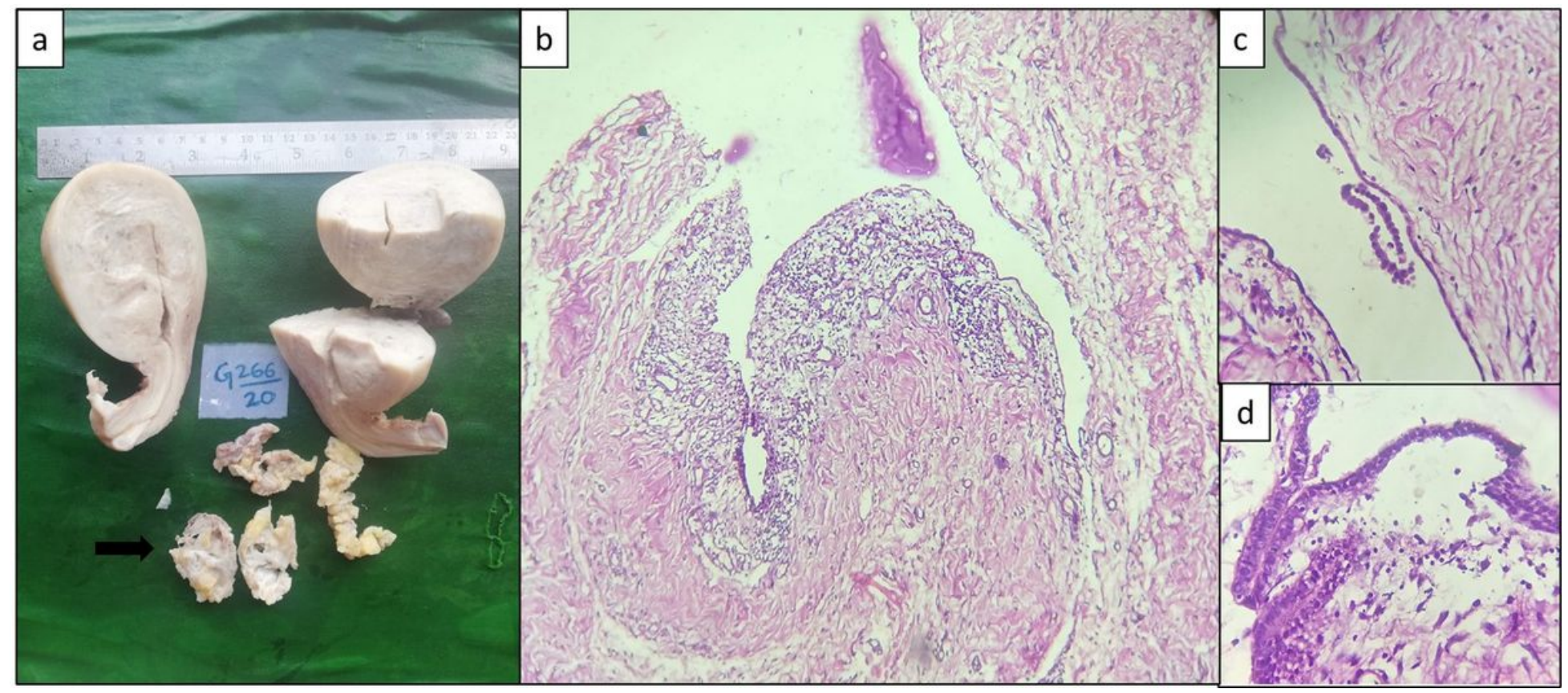

Figure 1

a) gross photograph showing uterus with cervix and peritoneal cysts (arrow), b) hematoxylin and eosin (H\&E), 40x, c) 100x d) 400x, cyst lined by single layer of mesothelial cells resting on fibro collagenous stroma and focal lymphocytic infiltrate 


\section{Supplementary Files}

This is a list of supplementary files associated with this preprint. Click to download.

- careguidelines.jpg 